\title{
Cooperação e coesão territorial no pacto federativo brasileiro: potencialidades e limites a partir de estratégias cooperativas intermunicipais nos estados da Bahia e do Rio de Janeiro*
}

\section{Juliana Nunes \& Antonio Angelo Martins da Fonseca}

\section{Introdução}

O debate sobre a coesão territorial remonta a uma discussão clássica da Geografia, mas que tem sido recentemente mobilizada nos debates acadêmicos que fazem alusão às estratégias de coordenação e colaboração, visando à superação dos efeitos deletérios das disparidades territoriais. (FARINÓS, 2008; FALUDI; PEYRONY, 2011). Nesse quadro, a expressão coesão territorial é componente do desenvolvimento, que se daria por meio da ativação das "sinergias" e das "potencialidades do território". Dentre os potenciais a serem ativados, inscreve-se uma diversidade de elementos materiais e imateriais, capazes de estimular ou dificultar articulações em benefício de interesses convergentes. Tratase, nesse sentido, de valorizar dimensões tangíveis e intangíveis de ordenamento das relações territoriais, muitas vezes balizadas por estratégias de negociações mais horizontalizadas e colaborativas em pactos político-territoriais.
Longe de se esgotar em uma simples geografia administrativa, o estudo dos arranjos, recomposições e diferentes formas de negociações territoriais mobiliza uma Geografia Política, no sentido amplo de que as relações de poder político que se materializam nas sociedades e recortam os espaços têm uma dimensão intrinsecamente territorial. No âmago desse debate, nossa reflexão se volta para as práticas cooperativas de gestão e coordenação territorial no contexto do regime federativo e democrático que se instituiu e se aperfeiçoa desde a promulgação da Constituição de 1988 no Brasil. Trazemos para o cerne da discussão os desafios para uma gestão territorial mais colaborativa, participativa e coordenada, que implica articulações intergovernamentais e coordenação do poder público e dos diversos atores e agentes da sociedade civil em arranjos táticos, visando à coesão territorial como resultado empírico e à justiça territorial como horizonte ético. (LIMA, 2015).

Sem pretender esgotar o tratamento do tema, que vem sendo objeto de discussões oportunas

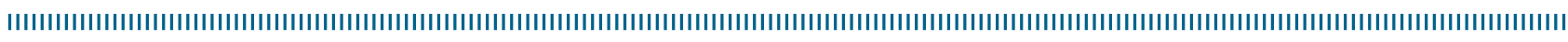
Como citar este artigo:

NUNES, Juliana \& FONSECA, Antonio Angelo Martins da. "Cooperação e coesão territorial no pacto federativo brasileiro: potencialidades e limites a partir de estratégias cooperativas intermunicipais nos estados da Bahia e do Rio de Janeiro". In: RÜCKERT, A. A.; SILVA, A. C. P. da; SILVA, G. de V. (Orgs.). Geografia Política, Geopolítica e Gestão do Território: integração sul-americana e regiões periféricas. Porto Alegre: Editora Letra1, 2018, p. 287-304 DOI 10.21507/9788563800367-18 
sobre novos modos de coordenação das ações políticas territoriais (FERRÃO, 2011; FARINÓS, 2008), o objetivo do texto é situar o debate recente sobre a coesão territorial e confrontá-lo às mediações político-institucionais e territoriais brasileiras. A expressão "coesão territorial” é aqui problematizada em suas múltiplas dimensões, a partir do debate acadêmico e político recente sobre processos de negociação, agenciamentos e recomposições territoriais. Ou seja, busca-se identificar os componentes frequentemente convocados em um debate que lança luz sobre arranjos territoriais cooperativos, a fim de melhor explorar as possibilidades teórico-metodológicas de apreensão de relações de conexão política e espacial.

Como possibilidade de exploração empírica, propõe-se a análise das relações entre estados federados e municípios em duas realidades políticas e territoriais particulares: o estado da Bahia e o estado do Rio de Janeiro. Esses dois estados federados constituem recortes de pesquisa interessantes: os dois têm como particularidade o fato de terem abrigado capitais brasileiras, e supõe-se que as relações federativas entre os estados e seus respectivos municípios tenham sido historicamente marcadas por essa condição; ademais, os dois estados empreendem estratégias diversas em relação às possibilidades de conformação de arranjos intermunicipais cooperativos para fazer face aos desafios sociais, econômicos e políticos. São essas estratégias e as peculiaridades das relações entre as escalas de poder estadual e municipal que nos interessam mais especificamente.

Propõe-se, assim, dar continuidade aos estudos acerca dos arranjos cooperativos intermunicipais, que constituem instrumentos estratégicos para a maximização dos recursos das economias e dos aparatos institucionais municipais. Nesse quadro, admite-se que os diferentes pactos políticoterritoriais que se diversificam e se ampliam no território brasileiro representam evidências que nos permitem melhor explorar as potencialidades e os gargalos das condições de passagem de um tipo de federalismo competitivo para um formato mais cooperativo e coordenado.
O texto se organiza da seguinte maneira: em um primeiro momento, tentaremos caracterizar a coesão territorial, a partir da identificação de alguns de seus atributos e de suas dimensões, evidenciados nos debates recentes sobre o tema. Em seguida, faremos uma sistematização de algumas propostas teórico-metodológicas voltadas para a análise das relações espaciais balizadas por uma lógica cooperativa e ditas orientadas para uma maior coesão territorial. O propósito, aqui, é identificar possibilidades analíticas acerca das relações de complementaridade entre espaços. Em uma terceira seção, procuramos trazer o debate para a realidade político-institucional e territorial brasileira. Na última seção, algumas possibilidades de arranjos político-territoriais que se configuram nas escalas subnacionais e que anunciam práticas cooperativas e participativas são enfim mobilizadas à luz de alguns exemplos empíricos de arranjos territoriais cooperativos que se configuram nos estados do Rio de Janeiro e da Bahia.

\section{A coesão territorial e suas dimensões: uma primeira aproximação}

A problemática esboçada se inscreve em um contexto de redefinição das diretrizes para se pensar o planejamento e a gestão territorial. Para alguns autores (PRECEDO LEDO, 2004; FERRÃO, 2011), trata-se de um contexto de valorização da assim chamada "seletividade espacial", em que atributos materiais e imateriais das diversas localidades são valorizados, em processos colaborativos e de coordenação para a construção de prospectivas que contam com ampla participação dos atores e agentes implicados. Em última instância, configura-se um debate sobre arranjos e desenhos institucionais capazes de acomodar novas formas de agenciamento do conflito político. Essa perspectiva nos remete ao problema fundamental que as instituições nos colocam enquanto "consolidações coletivas de formas de compreender, de agir e de organizar as interações em sociedade”. (REIS, 2009, p. 20). Em outras palavras, trata-se de compreender as interações colaborativas no âmbito de "sistemas 
coletivos que mobilizam várias estruturas sociais: o mercado, o Estado, a comunidade, as associações de interesses, as redes, as hierarquias empresariais" e que estão longe de promover convergência e homogeneidade. (REIS, 2009, p. 20).

O ressurgimento dos debates sobre coesão territorial ocorre, assim, em um contexto em que os instrumentos da ação pública foram profundamente modificados: a planificação e os "grandes programas" dão lugar à contratualização, às agências e a um recurso massivo à expertise. (SOUZA, 2006; FERRÃO, 2011). Ademais, essa perspectiva implica frequentemente a criação e a ampliação de canais que permitem à sociedade civil participar dos processos decisórios. Compreende, igualmente, o que se convencionou chamar de governança territorial - "boas práticas" que encerrariam o debate e a negociação entre diferentes atores e agentes do poder público e "do território" em vista da definição de objetivos comuns e a construção de um projeto coletivo de desenvolvimento. (PLANCHE, 2007). Trata-se de uma forma negociada da ação pública, fundada em arranjos de cooperação e de coordenação entre diversos atores e agentes, públicos e privados. (DALLABRIDA; BECKER, 2003).

Nessa perspectiva, se a ideia de governo se refere a um poder (do Estado), organizado por meio de relações hierárquicas e burocráticas, “a governança se refere à emergência de um novo sistema de relações, mais complexo, que inclui novos atores emergentes externos, à agenda política”. (FARINÓS, 2008, p. 12). Ainda para Farinós (2008, p. 15), “[...] a governança territorial é uma precondição para a coesão territorial, mediante a participação dos distintos atores (públicos, privados, terceiro setor...) que operam em diferentes escalas"1. Em se tratando de processos decisórios, esse modus operandi implica, inexoravelmente, conflitos de interesses e relações assimétricas.

IIIIIIIIIIIIIIIIIIIIIIIIIIIIIIIIIIII

1 Tradução dos autores. Versão original: [...] la gobernanza territorial es una pre-condición para la cohesión territorial, mediante la participación de los distintos actores (públicos, privados, tercer sector...) que operan a las diferentes escalas. (FARINÓS, 2008, p. 15).
Para alguns autores (LELOUP et al., 2005; PLANCHE, 2007), trata-se de um contexto privilegiado para experimentação de processos de construção coletiva de projetos futuros. Todavia, algumas questões que se referem à qualidade e à natureza da participação dos atores e agentes, à transparência dos processos decisórios, assim como à qualidade e à efetividade das interações, permanecem em suspenso. Afinal, até que ponto é possível se pensar em “consenso territorial”, já que se trata de ambientes dinâmicos e complexos, caracterizados essencialmente pelo conflito?

Nesse debate, o território constitui um sistema complexo e interativo, no qual intervêm dimensões materiais e imateriais inscritas na realidade socioeconômica e ambiental de parcelas do espaço considerado; o território, em poucas palavras, é um processo de construção a ser apropriado e valorizado. (PRECEDO LEDO, 2006, p. 141). Ademais, as múltiplas possibilidades de interpretações e ajustes em relação às particularidades dos territórios nos situam diante de uma miríade de estratégias de seletividade espacial. (PRECEDO LEDO, 2004). A encruzilhada não é nova, e remete à tensão inerente a um projeto geral de coesão que, ao mesmo tempo, inclua e potencialize as diversificadas possibilidades de ordenamento e coesão nas escalas subnacionais.

Nessa discussão, é interessante retomar o conceito de capital espacial, sugerido por Jacques Lévy (1999), e suas possibilidades e limites analíticos em sociedades muito desiguais. Desenvolvida por analogia ao conceito de capital na economia, a noção de capital espacial se desdobra de uma ampla discussão na Sociologia², que procura explorar as capacidades desiguais de aproveitamento de recursos e a produção de novos bens - materiais e imateriais.

O capital espacial se refere, nos termos de Lévy (2003), ao que distingue uma parcela do espaço considerado em termos de potenciais de desenvolvimento. Tais potenciais estão

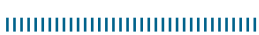

2 Esta discussão ultrapassa amplamente o escopo e os objetivos do presente texto; porém, as referências para o aprofundamento do debate podem ser encontradas em Lévy (1999; 2003). 
relacionados a um conjunto de elementos, tangíveis e intangíveis, que atribuem a esse espaço oportunidades ou dificuldades a serem suplantadas. Desdobra-se, igualmente, dessa acepção, a ideia de que as diversidades espaciais constituem trunfos a serem ativados por meio de relações colaborativas não apenas entre atores e agentes, mas também entre espaços. No âmago desse debate, a formulação "capital espacial" é instrumentalizada para se fazer referência ao conjunto de recursos, acumulados por um ator, que lhe permite extrair vantagens, em função de suas estratégias, das diversidades dos espaços de vida da sociedade. (LÉVY, 2003). A proposta de Lévy valoriza, em suma, as estratégias dos atores e agentes e a capacidade de ativação ou não dos recursos materiais e simbólicos disponíveis.

Nesse sentido, "o território mesmo é um recurso" (GUMUCHIAN; PEQUEUR, 2007, p. 7), a ser ativado segundo seus atributos de posição - em relação à sua materialidade e relatividade, por um lado; e em relação à sua localização, por outro lado - e suas características associadas ao seu potencial de desenvolvimento, em suas dimensões materiais/concretas e simbólicas/ideais, ao longo do tempo. A fricção do tempo é aqui um componente fundamental, já que a história é uma mediação importante para a conformação de processos de aprendizagem coletiva sobre os atributos disponíveis e as dificuldades a serem suplantadas.

Essa perspectiva nos remete a uma discussão clássica da Geografia Política; observe-se que já em Ratzel o senso geográfico dos povos deveria ser aguçado para se melhor usufruir dos recursos (materiais e simbólicos) e oportunidades de desenvolvimento. Vê-se aqui como a história das sociedades sempre foi importante para os processos de aprendizagem e a concepção de formas de atuação política capazes de evitar a desarticulação e a fragmentação dos subespaços nacionais - em Ratzel, tratava-se de se conhecer e de se apropriar do solo para melhor aproveitálo; fazia-se necessário organizar os fluxos e a circulação a fim de se garantir a articulação, a unidade e a coesão do território nacional. Para tanto, um componente ideológico - o nacionalismo
- deveria constituir a liga para o engajamento dos povos em um projeto político-territorial comum.

Exclusivamente o solo [boden] dá coerência material a um Estado, vindo daí a forte inclinação sobretudo da organização política de naquele se apoiar, como se ele pudesse forçar os homens, que de toda sorte permanecem separados, a uma coesão. Quanto maior for a possibilidade de fragmentação, tanto mais importante se torna o solo, que significa tanto o fundamento coerente do Estado quanto o único testemunho palpável e indestrutível de sua unidade. (RATZEL, 1987, p. 11)

Essas formulações inspiraram muitos outros debates na disciplina; pode-se fazer alusão às tendências centrífugas e centrípetas, que para Hartshorne (1950) se acomodam e promovem as diferentes formas de organização política de áreas. Ademais, não é ocioso evocarmos as contribuições de Jean Gottmann (1952; 1973), para quem forças de circulação e de resistência ao movimento, com seus componentes materiais e simbólicos, fundamentam as divisões políticas das sociedades no mundo; Dickinson (1961, p. 26), por sua vez, valoriza a importância dos diversos interesses comuns de determinada sociedade na definição de uma região política ideal. Para esse autor, uma "região política ideal, seja grande ou pequena, é aquela que possui o maior número de interesses comuns".

A busca da melhor forma para se promover a organização e a assim chamada "coesão territorial" fomenta, portanto, contribuições e formulações que se delineiam, direta ou indiretamente, desde os clássicos da disciplina. Mais recentemente, a expressão "coesão territorial" voltou à tônica justamente para se fazer referência às possibilidades de ativação de interações colaborativas entre subespaços inscritos em um todo (um território nacional, uma região), capazes de, ao mesmo tempo, promover a articulação e suscitar a complementaridade em prol de um projeto de desenvolvimento solidário entre "as partes". Essa solidariedade compreende, frequentemente, a valorização das diferentes "vocações" ou "oportunidades" dos territórios em uma dinâmica colaborativa, em diferentes escalas e também horizontalmente, que envolva a adoção de 
mecanismos ou estratégias de redistribuição de recursos em vista da redução das disparidades socioeconômicas. (PRECEDO LEDO, 2004). Nessa esteira, a coesão territorial remete a uma dinâmica de articulação e integração entre os espaços, de modo a se promover certo grau de coerência e complementaridade capaz de sustentar o desenvolvimento, vislumbrando-se, portanto, não a homogeneidade ou o equilíbrio, mas uma lógica propulsora de um processo de desenvolvimento socioespacial mais justo. (BRET, 2006; BRET et al., 2010; BRENNETOT, 2010; LIMA, 2015).

Dito isso, apesar de permanecer como uma expressão um tanto genérica e de certo modo imprecisa, é possível detectar, a partir do debate corrente sobre o tema, alguns componentes e dimensões das relações espaciais que nos auxiliam na apreensão das qualidades das conexões capazes de fomentar a coesão territorial.

Em uma primeira aproximação, a coesão territorial pode ser remetida a uma dimensão funcional - frequentemente associada à complementaridade das "vocações" e dos potenciais produtivos das partes constitutivas -, o que não implica a construção de relações de trocas solidárias orientadas a partir das particularidades de cada subespaço. (SILVA, 2014). Nesta compreensão, o território se torna o referencial supostamente pertinente e organizativo para mobilizar os esforços e os investimentos para a superação dos entraves ao desenvolvimento. (BERTRAND; PEYRACHE-GADEAU, 2009).

Cabe, neste ponto, atentar para a distinção entre complementaridade e dependência nas relações que se estabelecem entre os espaços (SILVA, 2014): a complementaridade é aqui entendida na perspectiva de cooperação recíproca que oportuniza o desenvolvimento socioeconômico dos subespaços considerados em conjunto, enquanto a dependência se configura quando um polo socioeconômico e/ou político explora a sua periferia e orienta em benefício próprio as relações, sem promover a difusão espacial do desenvolvimento. (BRET, 2001).

Nesse sentido, a dimensão funcional de complementaridade somente pode ser empreendida por meio do reconhecimento de horizontes comuns; quer dizer, é necessário que haja certa capacidade de agenciamento dos conflitos e de engajamento político orientado por objetivos conciliados. Isso significa que a ideia de coesão encerra uma dimensão eminentemente política, que implica um processo de construção de conexões de natureza colaborativa. (BUSSI; DAUDE, 2005; 2009; FARINÓS, 2008). Essa dimensão contratual se coaduna com os princípios da justiça territorial; ou seja, repousa, sobretudo, em um engajamento em prol da otimização das diferenças em favor dos espaços socialmente menos favorecidos (BRET, 2006), "através da distribuição mais equitativa de serviços, da busca pela ampliação da liberdade para atrair investimentos, da busca de poder para se inserir de forma mais direta nos processos de decisões, execuções e ações políticas". (FONSECA; SANTOS; BOROWSKI, 2016, p. 115). Em outras palavras, a dimensão política da coesão territorial está aqui caracterizada por um conjunto de conexões que visam à promoção do interesse coletivo de desenvolvimento que não se restringe ao crescimento econômico, mas se volta para a redução das disparidades socioeconômicas e ampliação das liberdades e oportunidades de decisão, de execução e de ação dos atores territoriais.

Nesse viés, a coesão territorial resulta de um pacto político-territorial que tem como horizonte o desenvolvimento socialmente e espacialmente justo. (BRET, 2006; BRENNETOT, 2010), e não é supérfluo lembrar que pactos políticoterritoriais são fundamentados em diferentes estratégias territoriais dos atores e agentes implicados. Tais estratégias derivam não apenas de objetivos econômicos e políticos ponderados, mas das representações e prospecções acerca do espaço considerado numa inscrição de passado, presente e futuro. As estratégias de coordenação, portanto, estão associadas ao desenvolvimento de relações de reciprocidade e à capacidade de prospecção dos atores, a partir de representações institucionais e territoriais estruturadas. As informações disponíveis são, nesse sentido, importantes para reduzir incertezas e para facilitar 
os processos decisórios, assim como as trocas e experiências passadas que possibilitam antecipar as estratégias dos parceiros. Entende-se, portanto, que as relações colaborativas são construídas historicamente a partir do estabelecimento de conexões que envolvem aspectos de ordem não apenas objetiva, mas notadamente política e simbólica.

Em suma, está-se aqui propondo uma apreensão da coesão territorial como uma resultante de práticas cooperativas entre atores e agentes, pautadas por um sistema de relações entre espaços articulados do ponto de vista econômico, político e simbólico, capazes de fomentar complementaridades para um desenvolvimento mais justo. Em outras palavras, a coesão territorial supõe o engajamento e a articulação dos atores e agentes em modos de organização dos conflitos mais horizontalizados, orientados para a ampliação do acesso a direitos no território.

Contudo, a grande dificuldade se manifesta quando se problematizam as condições ou aspectos facilitadores (as experiências passadas, as particularidades socioeconômicas e espaciais) da coesão territorial. (BERTRAND; PEYRACHEGADEAU, 2009). Para melhor aprendermos essa dificuldade e melhor delimitarmos os traços que nos possibilitam caracterizar a coesão territorial, passemos à seção seguinte.

\section{Relações espaciais para a coesão territorial: algumas propostas teórico- metodológicas}

Diante do exposto, convém questionar em que medida os contextos territoriais podem ser estruturantes para se compreender insucessos ou experiências exitosas de desenvolvimento. (BERTRAND; PEYRACHE-GADEAU, 2009, p. 89). Em outras palavras, em que medida os assim chamados "contextos territoriais" são passíveis de conformar agenciamentos mais ou menos favoráveis às interações colaborativas? A coordenação, no sentido de ordenação conjunta, é, portanto, longe de ser evidente, consensual e estanque. Antes, resulta de processos de negociação entre atores e agentes possivelmente capazes de construir prospectivas e atuar de forma a ativar ou não os "potenciais", a partir das informações disponíveis, as formas de interação pretéritas e, sobretudo, o ambiente institucional em que se inscrevem. (NORTH, 1990; OFFNER, 2006).

Neste ponto, é possível avançar a reflexão acerca das mediações institucionais ${ }^{3}$ que orientam as práticas políticas nos espaços subnacionais. (HALL; TAYLOR, 1997). As instituições, formais e informais, consistem em regularidades que afetam os comportamentos, ou, em uma concepção frequentemente evocada, as instituições são as "regras do jogo". (NORTH, 1990). O jogo é aqui entendido como as próprias interações entre atores e agentes, e as instituições, os pressupostos que norteiam as interações, atribuindo-lhes previsibilidade, estabilidade e credibilidade. Essa aproximação teórico-metodológica é convidativa para os geógrafos se inserirem mais ativamente no debate sobre as possibilidades de ativação dos recursos materiais e imateriais presentes nos diversos subespaços nacionais ${ }^{4}$. Não obstante, cabe

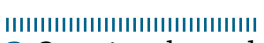

30 assim chamado "quadro institucional" consiste em todo um conjunto de constrangimentos de ordem material, moral ou cognitiva, formais ou informais - convenções, códigos de conduta, contratos, leis etc. - suscetíveis de afetar os comportamentos e as escolhas individuais e coletivas. Trata-se, grosso modo, de aspectos tangíveis e intangíveis capazes de influenciar a interpretação das informações disponíveis e de condicionar ações e decisões. Ver MARCH, James; OLSEN, Johan. Rediscovering Institutions: The Organisational Basis of Politics, New York, Free Press, 1989.

4 No campo da Geografia, o geógrafo francês Michel Lussault definiu "instituição" da seguinte maneira: "Instituir é estabelecer alguma coisa, em princípio pela primeira vez e de forma durável”. O autor amplia em seguida sua definição, ao precisar que podemos conceber "instituição" como um conjunto de objetos (materiais ou imateriais) instituídos por uma organização qualquer e que, uma vez instituídos, permanecem "ativos" socialmente [...]. "A instituição assim considerada é um dos recursos que o ator espacial mobiliza em suas ações". Tradução livre da autora. Versão original: «Dans une perspective d'analyse pragmatique de la spatialité des sociétés, [...] on peut tenter de définir l'institution comme l'ensemble des objets (qu'ils soient immatériels, idéels, matériels, fixés dans des choses et des dispositifs) institués par une organisation quelconque [...] qui, en tant qu'ils sont institués, demeurent actifs socialement une fois qu'ils ont été créés, donc visibles et utilisables par les opérateurs sociaux en même temps qu'ils leur offrent du répondant ou/et leur imposent des contraintes - où l'on retrouve à la fois le caractère institué et le caractère instituant de l'institution [...]». «L'institution, ainsi considérée, est une des ressources que l'acteur spatial mobilise dans ses actes.» Ver Lussault (2003, p. 514-516). 
salientar que essa perspectiva abrange uma gama variada, ampla e complexa de correntes teóricometodológicas, e não é nosso objetivo esmiuçálas neste texto. Por ora, atentemos para algumas formulações que iluminam alguns aspectos subjacentes para a conformação de relações espaciais mais colaborativas que conflitivas, balizadas pela busca de desenvolvimento e coesão territorial.

Nessa direção, o geógrafo francês Michel Bussi (2009a; 2009b), ao analisar as formas de cooperação que se estabelecem entre comunas na França, procurou sistematizar um modelo de análise das práticas cooperativas entre espaços. O autor desenvolve uma tipologia teórica para formalizar as condições que levam à cooperação territorial e os arranjos que daí se desdobram. Tomandose como base algumas referências da economia política (AXELROD, 1984; CORDONNIER, 1997; TAZDAÏD, 2005 apud BUSSI, 2005; 2009a), Bussi identifica três tipos-ideais de cooperação:

- A cooperação por semelhança ou "comunitária”, que reuniria unidades político-territoriais semelhantes do ponto de vista sociocultural e mesmo econômico. De acordo com essa tipologia, "nós cooperamos porque nos parecemos", e podem-se defender interesses "corporativos, étnico-culturais, religiosos, partidários comuns...".

- Acooperação "estratégica", cujo motor propulsor seria justamente a forte competitividade entre espaços, em um contexto de globalização econômica. Nessa lógica, "nós cooperamos para maximizar um ganho individual". Nessa esteira, um território pouco competitivo deve necessariamente cooperar com outros, a fim de melhor se inserir no mercado e se beneficiar dos ganhos advindos por meio da cooperação.

- A cooperação “subsidiária”, que estaria fundamentada em interesses coletivos, valores superiores e fatores externos ao território da cooperação, como os interesses "da Nação" e a perspectiva ética (a justiça e o bem comum...). Novas demandas resultantes de reformas político-institucionais ou um marco legal estabelecido em prol de valores comuns seriam, portanto, exemplos de fatores externos.

Não é demais lembrar que essas diferentes lógicas não ocorrem em estado puro, mas estão frequentemente amalgamadas e constituem pontos de partida para avançarmos na nossa reflexão sobre os componentes capazes de fomentar relações espaciais mais cooperativas, estratégicas para a coesão territorial. Esse modelo de análise é, portanto, significativo na medida em que nos possibilita ampliar a reflexão sobre possíveis lógicas capazes de impulsionar a adoção de práticas cooperativas.

Acrescente-se que os debates correntes sobre o tema assumem um caráter cada vez mais normativo e programático, haja vista a invocação da expressão "coesão territorial" em documentos oficiais. Nesse bojo, decretou-se no Tratado de Lisboa (2007) que a coesão territorial é um objetivo a ser buscado pelos Estados-membros da União Europeia. Mas, como muitos autores têm destacado (DAVOUDI, 2005; FALUDI, 2010, 2005, 2004; OTHENGRAFEN; CORNETT, 2013; SERVILLO, 2010; VAN WELL, 2012), não há qualquer definição clara sobre o que a "coesão territorial" possa efetivamente significar. Faludi (2005, 2004) assevera que a proposta de coesão territorial é propositadamente vaga; trata-se de um conceito a ser negociado, e é essa imprecisão que o torna justamente tão relevante nos processos de construção de políticas territoriais ${ }^{5}$. Ou seja,

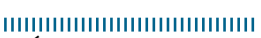

5 É interessante aqui pontuar que Andreas Faludi (2004) identifica as origens da concepção europeia de "coesão territorial" a partir da abordagem francesa de "aménagement du territoire" e do desenvolvimento econômico regional. A expressão "aménagement du territoire" é de difícil tradução para o português. Remete à ideia de planejamento e de gestão territorial. Em sentido amplo, tem como objetivos a superação das disparidades territoriais e a promoção de um desenvolvimento "mais harmonioso" e integrado, considerando-se as particularidades territoriais. Para o autor, o livro icônico que inaugura com clareza essa perspectiva é Paris et le désert français, de Jean-François Gravier, publicado em 1947. O referido livro inspirou diversas políticas territoriais de superação de disparidades e preconizou uma reflexão sobre a importância do compromisso dos atores e agentes regionais e locais para se pensar o território nacional de uma perspectiva policêntrica, e não apenas a partir da centralidade econômica e política parisiense. Mais tarde, a partir dos anos 1960, o referido livro viria a inspirar 
a fórmula não está acabada, mas deve resultar de processos de concertação sobre os interesses comuns e as oportunidades a serem explorados. Reforça-se, assim, uma dimensão eminentemente política, que no âmbito do projeto europeu se orienta por propostas de maior integração entre os Estados e de maior articulação entre suas regiões. Trata-se de agregar ações e decisões a fim de se aperfeiçoar os "pontos fortes" e fomentar iniciativas de cada subespaço considerado.

Desse modo, a despeito de a coesão territorial ser evocada como um objetivo difuso a ser alcançado, no contexto de integração do continente europeu assumem-se certas diretrizes que orientam os processos de elaboração de políticas nessa escala: um deles é a busca de um maior equilíbrio quando se trata de pensar o desenvolvimento. O "equilíbrio" aqui se refere, uma vez mais, à acomodação (e não à supressão) das diferenças, sobretudo entre as regiões dos países que fazem parte do bloco. Daí se desdobram as estratégias e os mecanismos de ativação das particularidades desses subespaços como potenciais para fomentar o desenvolvimento de forma "sustentável". Nessa perspectiva, quando da publicação do Livro Verde sobre a Coesão Territorial (2008), a Comissão Europeia adotou a coesão territorial como um objetivo associado à "garantia de um processo de desenvolvimento "sustentável" de todos os territórios, de modo que seus habitantes usufruam da melhor forma das suas características particulares". 6 (DAVOUDI, 2005; BERTRAND; PEYRACHE-GADEAU, 2009; VAN WELL, 2012). A assim denominada "Política de Coesão Territorial

||IIIIIIIIIIIIIIIIIIIIIIIIIIIIIIIIII

muitas das políticas de descentralização e de valorização das regiões francesas, a partir de suas cidades principais. Faludi se refere, em síntese, a um "modelo de sociedade", em que as dimensões econômica e política não estão descoladas da dimensão territorial para se pensar o desenvolvimento. Por outro lado, a influência da tradição alemã também foi importante para incorporação de uma abordagem abrangente de coerência e coordenação integradas entre setores e entre escalas de gestão no âmago do significado da política de coesão territorial europeia.

6 Tradução livre da autora. Versão original: «la cohésion territoriale est un but à atteindre et doit garantir le développement durable de tous les territoires et permettre à leurs habitants de tirer le meilleur parti de leurs caractéristiques propres» (BERTRAND; PEYRACHEGADEAU, 2009, p. 89). da União Europeia" estabelece enfim como modus operandi a colaboração em rede para tornar as regiões mais competitivas no mercado. (FALUDI, 2005, 2004; DAVOUDI, 2005).

$\mathrm{Na}$ tentativa de sistematização da abordagem da "coesão territorial" nos debates recentes sobre o tema, o geógrafo português Eduardo Medeiros (2005; 2012) propõe um modelo de análise a partir da identificação de alguns elementoschave aos quais frequentemente se faz alusão no debate político e acadêmico. A matéria-prima das análises de Medeiros são, no entanto, os relatórios publicados pela Comissão Europeia.

A primeira observação de Medeiros (2012) focaliza a importância conferida aos aspectos socioeconômicos para se avaliar a coesão territorial. Tanto que, para Medeiros, a dimensão territorial é por vezes reduzida à análise de indicadores socioeconômicos do espaço considerado, tais como o PIB, os níveis de desemprego, os indicadores de renda, o grau de escolaridade, além dos indicadores de acesso aos serviços públicos os mais fundamentais, para ficarmos em alguns exemplos $^{7}$. (MEDEIROS, 2012, p. 4). Todavia, segundo o autor, a dimensão espacial foi sendo paulatinamente incorporada às abordagens sobre o tema, sobretudo com a valoração das redes de cidades e das relações cidade-campo como componentes importantes para a promoção de um modelo de desenvolvimento socioespacial mais integrado e articulado. (ESPON, 2006, apud MEDEIROS, 2012). É, porém, a partir dos relatórios dos anos 2007, 2010, e notadamente no Relatório Barca (BARCA, 2009) que, para o autor, a dimensão territorial ganha fôlego com a menção à importância do desenvolvimento sustentável, além da valorização dos conhecimentos e das particularidades locais no receituário da agenda política europeia.

Para além dos significados atribuídos pelos relatórios da CE, Medeiros empreende um esforço metodológico na construção de um

IIIIIII|||||||||||||||||||||||||||||||

7 O autor cita WISHLADE, 2008; FLORIO, 2006; MAIRATE, 2006; LEONARDI, 2006, GIANNIAS et al., 1999; GUERSENT, 2001; MARTIN; TYLER, 2006; BATTERBURY, 2006; BACHTLER; WREN, 2006; BADINGER et al., 2004, e CRESCENZI, 2009. 
modelo de análise da "coesão territorial". O autor toma como referência algumas tentativas de sistematização dos próprios relatórios da Comissão Europeia e a proposta de Camagni (2005 apud MEDEIROS, 2012), que identifica três pilares para a abordagem da coesão territorial, a saber: a eficiência territorial, baseada em aspectos econômicos e no uso dos recursos; a qualidade territorial, com base na qualidade de vida e do meio ambiente; e a identidade territorial, que estaria fundamentada na existência de "capital social" e no compartilhamento de referências e valores comuns. Medeiros desenvolve então sua proposta de abordagem agregando um amplo leque de aspectos a serem considerados, mas que podem ser agrupados em quatro eixos analíticos principais: a) a análise das disparidades socioeconômicas, que focaliza a distribuição dos recursos; b) a análise de políticas associadas à valorização do meio ambiente e ao consumo de energia, componentes vinculados à promoção do desenvolvimento sustentável; c) a análise da rede urbana (morfologia, hierarquia, relações); e d) a análise das relações de cooperação e governança territorial, que considera estratégias e interações horizontais e verticais (interescalares);

$\mathrm{O}$ autor sugere então a seleção de alguns indicadores para a avaliação de cada um desses eixos, que deverão compor um quadro de análise da intensidade e da qualidade das interações espaciais em diferentes contextos ${ }^{8}$.

Apesar das dificuldades expressas, essa proposta teórico-metodológica nos parece tanto mais interessante na medida em que evidencia as possibilidades de se desenvolver estudos comparativos, que nos permitem problematizar as mediações para a conformação de uma miríade de pactos político-territoriais em sociedades e em territórios diferentes. No entanto, e uma vez mais, antes de qualquer tentativa apressada de importação de modelos, convém atentar para a complexidade do debate em sociedades e territórios

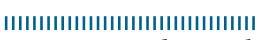

8 Por meio da combinação de indicadores e a construção de um índice, Medeiros analisa componentes da coesão territorial em países da Península Ibérica, da Escandinávia, e também em um conjunto mais amplo de países europeus. muito desiguais, como é o caso brasileiro.

De todo modo, Rückert (2013) nos lembra de que os princípios norteadores das políticas de coesão territorial na União Europeia influenciaram amplamente a agenda das políticas territoriais recentes em diversos países no mundo e, especialmente no caso brasileiro, os termos da assim chamada "Nova Política Nacional de Desenvolvimento Regional (PNDR)". Esta última prenunciou os objetivos de "reduzir as desigualdades regionais e ativar os potenciais de desenvolvimento das regiões brasileiras" (BRASIL, 2005), além de "promover a dinamização das regiões e a melhor distribuição das atividades produtivas no território". (BRASIL, 2005). Ademais, a OCDE chega a sinalizar, em suas avaliações, os principais desafios institucionais e territoriais para a promoção do "desenvolvimento territorial endógeno" no Brasil. Seriam eles: (a) fragmentação multidimensional das políticas (tanto setoriais quanto geográficas); (b) o federalismo fiscal e o desafio de lidar com a autonomia financeira e política de governos subnacionais; $\mathrm{e}(\mathrm{c})$ a superação das assimetrias de informação, fortalecimento da capacidade institucional e administrativa dos níveis subnacionais (em particular, em municípios com deficiências). (OCDE, 2011, p. 20-21 apud RÜCKERT, 2013, p. 64).

Em síntese, a coesão territorial é um tema que tem mobilizado esforços teórico-metodológicos voltados para a compreensão de novos contornos e articulações político-territoriais. (BUSSI, 2009). Com efeito, no Brasil e em outros países do mundo, assistimos a experiências que valorizam a descentralização política e as práticas colaborativas e participativas entre atores e agentes locais em diversificados arranjos e escalas da decisão e da ação pública territorial. Contudo, sabe-se que a estrutura federativa brasileira historicamente se caracterizou pela perenidade de relações competitivas. Ademais, marcos regulatórios pouco claros parecem dificultar a coordenação das escalas federadas e a convergência das ações nos processos de elaboração de políticas públicas. São sobre as particularidades político-institucionais e territoriais brasileiras que propomos nos debruçar na seção seguinte. 


\section{Coordenação e coesão territorial no pacto federativo brasileiro}

No contexto brasileiro, a expressão "coesão territorial" remonta a projetos de integração nacional e crescimento (econômico), que fomentaram propostas de gestão e de intervenção no território em suas diversas escalas, notadamente as escalas regionais ${ }^{9}$. Nessa esteira, não são poucas as análises que demonstraram o quanto tais projetos estiveram orientados por uma lógica eticamente injusta, e por vezes acentuaram mais do que contribuíram para reduzir relações centro-periferia de dependência e a fragmentação territorial nas escalas subnacionais. (BRET, 2001; 2006).

Interessa-nos, porém, o contexto políticoinstitucional inaugurado a partir da Constituição de 1988, que privilegiou um formato de federalismo relativamente mais descentralizado e impulsionou novas alternativas de pactos político-territoriais nas escalas subnacionais, em um processo de resgate e ampliação da democracia no País.

Com efeito, no federalismo brasileiro, momentos de maior ou menor descentralização foram alternados nos textos constitucionais, sendo redefinidas atribuições e competências para a implementação de políticas e a partilha de recursos entre estados, municípios e Governo Federal. No entanto, é a partir da Constituição de 1988 que a autonomia política de estados e municípios foi efetivamente assegurada em texto constitucional, mesmo que o escopo dessa autonomia seja ainda pouco claro e limitado pelo poder de supervisão do Governo Federal. (ARRETCHE, 2012). De todo modo, é a partir desse marco institucional que se ampliam os papeis e as possibilidades das escalas subnacionais, sobretudo municipais, nos processos de decisão e de execução de políticas públicas nos recortes territoriais locais.

||I||||||||||||||||||||||||||||||||||

9 Entre muitas outras referências, pode-se citar BECKER, B.; EGLER, C. Brasil: uma nova potência regional na economia-mundo. Rio de Janeiro: Bertrand Brasil, 2011. Em seus artigos de 2001 e 2006 supracitados, Bernard Bret mostra o quanto as propostas de integração territorial, inscritas no processo de "modernização conservadora" no Brasil, foram, de uma perspectiva da justiça socioespacial, excludentes.
Para além da reorganização dos poderes territoriais, a Carta estabeleceu diretrizes que valorizaram o dito "federalismo cooperativo", que pressupõe competências difusas e compartilhadas entre as três escalas decisórias ${ }^{\mathbf{1 0}}$. Tais mudanças trouxeram novos desafios para a coordenação de ações e definição de políticas conjuntas entre as três escalas territoriais da decisão. Em outras palavras, considerando-se a autonomia de cada ente federativo, a complexidade do federalismo brasileiro resulta dos acordos e negociações que se estabelecem entre Governo Federal, estados e municípios para acomodar os conflitos e estimular a assunção de responsabilidades. Assim, ganharam relevo as ações deliberadas das escalas de gestão superiores para tornar a descentralização atrativa para as escalas de gestão subnacionais. (ARRETCHE, 2000). Precisamente, as estratégias de incentivo e os constrangimentos legais - por meio da transferência ou não de recursos técnicos, financeiros e humanos, como contrapartida à assunção de responsabilidades - são peça-chave para o sucesso da transferência de atribuições nos mais diferentes setores das políticas públicas.

Por outro lado, é também a partir dos anos 1990 que se intensificam as práticas de concessão de isenções de impostos por estados e municípios. (OLIVEIRA, 1995). As escalas subnacionais, buscando atrair capitais e empresas privadas para seus territórios, passaram a conceder benefícios fiscais e intensificaram as transações com as redes de comércio mundial, iniciando uma verdadeira guerra fiscal. Sobre isso, argumentou-se que:

A perda da capacidade articuladora da União e a sua não substituição por outras formas de regulação (mais federalizadas, cooperativas e descentralizadas) ocorreram em um contexto no qual a crise econômica e fiscal acirra as disputas estruturais entre as unidades

IIIIIIIIIIIIIIIIIIIIIIIIIIIIIIIIIIII

10 federalismo cooperativo se caracteriza pela predominância de competências compartilhadas entre as escalas de poder. Isso significa que os estados federados, os municípios e o Governo Federal não devem atuar de maneira independente, mas de maneira coordenada, o que possibilita maior flexibilidade para concepção e execução de políticas e programas comuns. Ver LOSADA, Paula Ravanelli. A Lei dos Consórcios Públicos: uma estratégia de fortalecimento da Federação brasileira para o desenvolvimento econômico e social, mimeo, 2008, p. 2. 
federadas, acentuando a operação de forças centrífugas desagregadoras, tanto internas quanto externas. (AFFONSO, 1995, p. 69).

Assim, muitos estudiosos do federalismo brasileiro (AFFONSO, 1995; AFONSO, 1995; FIORI, 1995; RODRIGUEZ, 1995) consideraram que, em função das novas relações entre as economias das unidades subnacionais e as redes de produção e comércio internacionais, um dos principais desafios para o Federalismo brasileiro seria a competitividade entre unidades políticoadministrativas. Nessa perspectiva, afirmou-se que o pacto federativo brasileiro estaria sendo afetado por "forças centrífugas" que tenderiam a "esgarçá-lo" (AFFONSO, 1995, p. 59) e a comprometer a coesão territorial.

No entanto, estudos recentes têm demonstrado que os conflitos entre as escalas federativas e o problema das disparidades são, no âmbito pacto político-territorial adotado no Brasil, "uma contradição em termos”. (ARRETCHE, 2012). Em primeiro lugar, as disparidades territoriais estariam, historicamente, no cerne do desenho político-institucional adotado no Brasil. E em segundo lugar, a despeito da competição entre as escalas e as unidades subnacionais, a Constituição de 1988 assegurou o papel do governo central para regulação das políticas e redistribuição de recursos, além de ter primado pela coordenação federativa. Com efeito, a Constituição garante ampla competência legislativa para o Governo Federal e vincula as capacidades de gasto das unidades subnacionais nos setores de políticas públicas os mais fundamentais, como saúde e educação ${ }^{11}$. Adicionalmente, não por acaso, são esses os setores que mais contam com a adoção de desenhos institucionais de cooperação federativa para a elaboração e a execução de políticas, como é o caso dos Consórcios Intermunicipais, citados nas normas do Sistema Único de Saúde (SUS) e

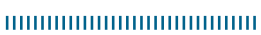

11 Em estudos recentes, Martha Arretche demonstra como, a partir dos anos 1990, ampliaram-se os instrumentos institucionais de controle de gastos das escalas subnacionais, "de modo a garantir que as receitas locais sejam efetivamente destinadas a realizar objetivos políticos estabelecidos pelas arenas decisórias federais". (ARRETCHE, 2012, p. 201). regulamentados pela Lei dos Consórcios Públicos (2005) e o decreto complementar que se seguiu, em $2007^{12}$.

A Lei dos Consórcios Públicos foi regulamentada com o objetivo de sanar incertezas e definir modalidades e regras para a cooperação a fim de estimular uma atuação mais relacional e colaborativa no desenvolvimento de projetos de gestão compartilhada nas escalas subnacionais. Nesse sentido, a cooperação entre municípios é reconhecida como um instrumento importante para aperfeiçoar o uso e a gestão de equipamentos, infraestruturas e serviços públicos. Interessante salientar que, como os Consórcios de Saúde bem exemplificam, os Consórcios não preveem uma distribuição territorial igualitária de bens e serviços, mas estão pautados por uma lógica de hierarquização na distribuição territorial de equipamentos e prestação de serviços, orientada segundo as características particulares de cada município, considerando-se inclusive as relações de oferta e procura por serviços públicos no âmbito do "território da cooperação" ${ }^{13}$. Ou seja, alinhamse à lógica da coesão territorial direcionada para a otimização dos recursos disponíveis e oportunização das diferenças, a fim de se garantir que todos os espaços "ganhem" por meio da coordenação das ações.

Contudo, dez anos após a referida legislação, muitos são ainda os desafios para a consolidação de relações mais colaborativas (RODRIGUES, 2010; 2012) do que conflitivas. Afinal, práticas cooperativas resultam de processos de aprendizagem e da construção de relações de reciprocidade, que não se dão por decreto. Além disso, há persistentes lacunas político-institucionais para um amplo leque de políticas (RODRIGUES; MOSCARELLI, 2015), sobretudo as de desenvolvimento urbano,

|||||||||||||||||||||||||||||||||||||

12 Lei 11.107 sobre os Consórcios Públicos Intermunicipais e o Decreto n. 6.017 de 2007.

13 A política de regionalização da saúde inscrita nas normas operacionais do Sistema Único de Saúde são os exemplos mais ilustrativos desse modelo, que incentiva a formação dos Consórcios Intermunicipais para uma gestão compartilhada dos serviços e equipamentos de saúde, segundo a capacidade técnica instalada em cada município, o número de habitantes e outras características particulares. Para mais detalhes, ver Rodrigues (2010, p. 391-398). 
que incluem transportes públicos, meio ambiente e infraestrutura. Some-se a isso o fato de que a maior parte dessas experiências não visa ao desenvolvimento de projetos territoriais. Antes, o objetivo é elaborar e executar políticas públicas setoriais, em contraste com uma perspectiva de coesão e desenvolvimento territorial mais abrangente.

Para além dos Consórcios Intermunicipais, Cruz et al. (2012) identificam no Brasil uma pluralidade de experiências cooperativas tanto horizontais (intermunicipal, interestadual) quanto verticais (entre União, estados federados e municípios). Os muitos exemplos apresentam uma "multiplicidade de formatos possíveis" (STRELEC; FONSECA, 2011, p. 130), em escalas de gestão as mais diversas, graças às alternativas previstas na Lei dos Consórcios Públicos, que possibilita inclusive a formação de consórcios entre municípios não limítrofes, ou, ainda, pertencentes a diferentes estados da Federação, além das possibilidades de arranjos entre municípios e estados federados. (STRELEC; FONSECA, 2011).

Nessa esteira, pactos político-territoriais mais colaborativos e participativos constituem uma alternativa às clássicas políticas territoriais estabelecidas "de cima para baixo", em um modelo de Estado federativo mais democrático. Entretanto, tal perspectiva é ainda incipiente e embotada por dificuldades que se apresentam nas escalas locais e pelos meandros das relações intergovernamentais e das relações governosociedade. Cabe, assim, aprofundar a reflexão sobre as mediações institucionais para a "cooperação subsidiária" e as dimensões (funcionais, políticas e simbólicas) pertinentes à compreensão dos arranjos territoriais cooperativos no âmbito da realidade brasileira.

Por fim, algumas possibilidades de desdobramentos empíricos podem ser vislumbradas, a partir da seleção de exemplos de arranjos político-territoriais que se configuram nas escalas subnacionais e que anunciam práticas mais colaborativas e participativas, visando à coesão territorial.

\section{Estratégias cooperativas nas escalas subnacionais: possibilidades e limites de articulações colaborativas nos estados do Rio de Janeiro e da Bahia}

A partir do universo dos municípios baianos e fluminenses, intenta-se melhor compreender as relações federativas capazes de estimular as práticas cooperativas entre os municípios. Acredita-se que a dinâmica das relações entre os recortes político-administrativos e entre as escalas estadual e municipal guardam, nesses dois estados federados, particularidades que remontam às suas trajetórias políticas no contexto federativo brasileiro: ambos abrigaram capitais federais - Salvador, do século XVI ao século XVIII, e Rio de Janeiro, do século XVIII até meados do século XX -, e os processos de desmembramento de municípios foram eminentemente marcados pela ascendência de elites políticas e econômicas e pelos conflitos entre a capital - centro político e econômico de projeção nacional - e o interior.

O estado do Rio de Janeiro contava, em 2005, com um total de 92 municípios e 119 Consórcios Intermunicipais setoriais ${ }^{\mathbf{1 4}}$. Nesse conjunto, 51 Consórcios estavam voltados para a prestação de serviços e a instalação de equipamentos na área da saúde, e os outros 68 distribuídos nas áreas de meio ambiente, saneamento, educação, assistência social, direitos da criança e do adolescente, transportes e turismo, dentre outros de menor expressão. No entanto, um levantamento realizado em 2008 apontou que apenas os Consórcios de Saúde estavam efetivamente instalados e em funcionamento, os demais se restringindo a experiências pontuais de cooperação para a execução de programas de curta duração ${ }^{15}$. Dessa maneira, tanto com relação aos objetivos quanto às metas alcançadas e a duração, as experiências em matéria de cooperação intermunicipal encontradas remetiam a um subaproveitamento

|||||||||||||||||||||||||||||||||||||

14 Dados da Pesquisa Perfil dos Municípios Brasileiros, IBGE, 2005.

15 Entrevistas de campo realizadas em julho de 2012, cuja metodologia e resultados podem ser consultados em Rodrigues (2010). 
desses instrumentos de gestão municipal. Por outro lado, as mesmas pesquisas indicaram que 85\% dos municípios fluminenses apresentavam problemas referentes à instalação e à manutenção de equipamentos e infraestruturas básicas para o provimento de serviços de educação, transporte e saneamento. Diante desse quadro, cabe aprofundar a investigação sobre as dificuldades dos municípios fluminenses para a adoção de estratégias colaborativas e participativas, voltadas para uma melhor cobertura de serviços e equipamentos públicos nas suas diversas regiões.

Pesquisas anteriores demonstraram que as relações centro-periferia predominam no estado e se reproduzem no âmbito das estruturas de cooperação intermunicipal. Ademais, há uma falta de correspondência entre os limites dos Consórcios Intermunicipais criados para diferentes setores de políticas públicas; de acordo com o setor da política pública considerada, a cooperação intermunicipal assume desenhos e recortes distintos, o que dificulta a perenidade das relações cooperativas entre municípios. Em outras palavras, mais do que territorial, a cooperação intermunicipal parece seguir o modelo setorial fragmentado das políticas públicas, muitas vezes estimulado pelas próprias regionalizações diferenciadas estabelecidas pelo governo do estado.

No estado da Bahia, por outro lado, o governo do estado passou a adotar, a partir 2007, uma série de inovações institucionais, políticas e territoriais, que apontavam para uma nova forma de relação estado/território. Se as tradicionais ações públicas estavam fundamentadas na centralização, na ausência de transparência e de diálogo com os diversos segmentos da sociedade, e no planejamento regional "de cima pra baixo" (FONSECA, 2005), nesse novo momento, deveriam ceder espaço para formas mais horizontalizadas (PUTNAM, 1996) de negociação; ou seja, mais democráticas, descentralizadas, inclusivas e baseadas na gestão e no território. Tendo como base os limites dos Territórios Rurais, criados pelo Governo Federal em 2003 (que por sua vez, deram origem aos limites dos Territórios da Cidadania, em 2007), o governo do estado instituiu, em 2008, os assim chamados Territórios da Identidade e, a partir desses, foram formados os colegiados territoriais que seriam as instâncias mediadoras nas relações entre o estado e os "territórios".

Observa-se que a correspondência entre esses Territórios de Identidade para a elaboração de políticas públicas nessa escala acaba por criar vínculos entre municípios que se articulam do ponto de vista econômico, social e político. A alusão a uma suposta "identidade territorial" é aqui também ativada como elemento agregador:

O conceito de Território da Identidade considera critérios
econômicos, geográficos e culturais na definição desses
limites, a priori reconhecidos pela população como um
espaço historicamente marcado por características
culturais particulares e por uma certa coesão social
e territorial. (Art. $1^{\circ}, \S 1^{\circ}$, do Decreto n. $12.354 / 10$,
BAHIA, 2010).

Os assim chamados Territórios da Identidade se inscrevem, portanto, em uma lógica de descentralização da decisão e de regionalização das ações, visando-se a oportunizar um desenvolvimento global dos municípios inscritos em um mesmo Território da Identidade.

Desde então, foram realizadas algumas audiências territoriais, objetivando-se a construção de Planos Plurianuais participativos. Considerando-se que, historicamente, a relação Estado-sociedade civil-território na Bahia foi marcada pelo predomínio de vínculos verticalizados (PUTNAM, 1996) nos quais os canais de cooperação e de articulação entre municípios, assim como os de participação da sociedade civil, eram frágeis, inovações institucionais como esta inauguraram perspectivas para ampliar as possibilidades de interações mais colaborativas e de complementaridade, orientadas para uma maior coesão e justiça territorial.

O discurso e a prática política do governo do estado focados na gestão do território tomou novo fôlego a partir de 2009, quando passou a fomentar e a induzir a criação dos Consórcios Públicos Intermunicipais (CPIMs) como o principal formato de arranjo político-territorial voltado para a efetivação das políticas públicas 
municipais e regionais. E a base espacial para a institucionalização desses consórcios foram justamente os Territórios de Identidade. Para tanto, foi gerada uma grande mobilização governamental que envolveu atores de dentro e de fora do governo, como as secretarias (Secretaria do Planejamento - Seplan, Secretaria de Desenvolvimento Urbano - Sedur, Secretaria do Meio Ambiente - Sema, Secretaria de Desenvolvimento e Integração Regional - Sedir, Casa Civil e Secretaria de Relação Institucionais (Serin), os técnicos em planejamento, a União dos Prefeitos da Bahia e mais de $72 \%$ dos prefeitos do estado que faziam parte da coligação dirigida pelo Partido dos Trabalhadores (PT). Conforme enfatizou Rios (2015, p. 157):

O desenho institucional de formação e ampliação dos CPIMs emerge da iniciativa do governo do Estado em direção aos municípios, onde na escala local irá encontrar pouca resistência e principalmente divergências à forma com que essa política vem sendo conduzida. Um grande exemplo desse pacto consensual refere-se à homogeneização dos instrumentos normativos internos que regulamentam o funcionamento dos $\mathrm{CPs}$.

As ações desses Consórcios se dirigem notadamente para políticas rurais e de gestão dos recursos hídricos. $\mathrm{Na}$ atualidade, 29 consórcios na Bahia compreendem um total de 347 municípios. Nesse conjunto, a maior parte está localizada no semiárido baiano (SILVA, 2015), região onde estão concentrados os municípios com as maiores injustiças territoriais do estado, sobretudo relacionadas às dificuldades de acesso a serviços de saúde, de educação e de segurança.

Embora as análises de Silva (2015) e Rios (2015) apontem avanços em relação à qualidade das interações estado/sociedade civil e das conexões intermunicipais, ainda há gargalos que comprometem a efetividade desses instrumentos quanto às possibilidades de promoção de uma maior coesão territorial e de ampliação do acesso a direitos. Os avanços, conforme já enfatizado, referem-se sobretudo às novas perspectivas abertas para relações mais horizontais, caracterizadas por práticas descentralizadas, cooperativas e voltadas para a mitigação de disparidades territoriais.
Os gargalos, por outro lado, referem-se a questões de ordem notadamente política, tais como:

a. O gradativo esvaziamento dos "Territórios de Identidade" como "arenas" de debates e o fortalecimento dos consórcios como arranjos voltados mais para a base espacial do planejamento. Por consequência, há ingerência constante do governo do estado nos territórios não somente por meio de mecanismos de controle, mas, igualmente, por meio de indução de propostas (SILVA, 2015);

b. A diminuição de importância dos mediadores dos Colegiados Territoriais e a ampliação de mediadores oriundos dos consórcios, que são indicados em grande parte pelos chefes do executivo;

c. A diminuição da participação da sociedade nas decisões e ações;

d. A tendência à ausência de municípios de porte populacional e econômico muito distintos no âmbito de um mesmo consórcio. Isso está ocorrendo porque municípios mais ricos podem não aceitar o rateio para contribuir com mais recursos nos consórcios;

e. A falta de recursos, uma vez que algumas prefeituras não repassam suas cotas do rateio dos custos de administração dos consórcios.

Os exemplos aqui evocados constituem recortes empíricos passíveis de serem explorados em termos da qualidade e da efetividade das interações colaborativas em pactos político-territoriais que se difundem no Brasil contemporâneo. Considerandose que a persistência de padrões diferenciados de acesso a bens e serviços públicos ainda desafia intelectuais e gestores, formas de gestão territorial compartilhada constituem potencialidades para se fazer face às dificuldades técnicas, financeiras e infraestruturais que se apresentam nas escalas subnacionais. Entretanto, tal perspectiva é ainda incipiente e embotada por entraves que se apresentam nas escalas locais e pelos meandros das relações intergovernamentais, sobretudo associados às sobreposições de competências e à falta de clareza dos marcos que orientam as articulações 
político-territoriais. Tais aspectos serão alvo de aprofundamento empírico em etapas subsequentes da pesquisa. Por ora, buscou-se apresentar a sistematização de uma metodologia teórica para se escrutinar os atributos e as qualidades das interações colaborativas territoriais passíveis de promover maior coesão territorial, tendo como horizonte o princípio ético da justiça; ou seja, a ampliação do acesso a direitos no território.

\section{Considerações finais}

Este texto teve o objetivo de pautar o debate recente sobre a coesão territorial e empreender uma reflexão sobre suas possibilidades investigativas no âmbito do pacto federativo brasileiro. Para tanto, em um primeiro momento, procuramos identificar os principais traços que caracterizam a coesão territorial, evidenciados nos debates recentes sobre o tema. Em seguida, reunimos algumas abordagens teórico-metodológicas voltadas para a análise dos componentes das relações espaciais orientadas por uma lógica colaborativa e de complementaridade. Em uma terceira seção, procuramos situar o debate à luz da realidade político-institucional e territorial brasileira. Por fim, alguns exemplos de arranjos político-territoriais ancorados nas premissas da participação, da descentralização e da cooperação foram evocados como realidades concretas passíveis de serem investigadas empiricamente.

No conjunto de questões aqui suscitadas, a problemática de fundo parece remeter à forma como são acomodadas as tensões inerentes aos processos de decisão e de ação pública territorial, diante da intensificação da competitividade econômica nas escalas subnacionais e de um contexto de valorização das iniciativas locais. No contexto brasileiro, as relações que se estabelecem entre os recortes e as escalas político-administrativas, além das disparidades socioeconômicas, parecem constituir elementos que dificultam a coordenação de interesses e a definição de objetivos comuns. Apesar disso, novos arranjos e contornos da ação política territorial se delineiam, e os Consórcios Públicos Intermunicipais constituem um exemplo dessas iniciativas, fomentadas por marcos jurídicos que destacam o papel do Governo Federal e dos estados federados na indução de estratégicas cooperativas.

Posto isso, tivemos como perspectiva apresentar uma reflexão teórico-conceitual e as possibilidades metodológicas para melhor apreender os arranjos político-territoriais que se configuram em escalas subnacionais no Brasil contemporâneo. Considerem-se as promessas não apenas dos Consórcios Intermunicipais, mas também de outros formatos e contornos político-territoriais que propõem lógicas de desenvolvimento para além do crescimento econômico, sendo potencialmente propulsores de articulações mais colaborativas e inclusivas entre espaços. Trata-se, em suma, de um debate acerca das potencialidades e dos limites de estratégias negociadas da ação pública territorial, mediadas pelos marcos do nosso pacto federativo e pelas particularidades das relações que se inscrevem em contextos territoriais os mais adversos.

\section{Referências}

AFFONSO, R. B. A. A Federação no Brasil: impasses e perspectivas. In: SILVA, P. L. B.; AFFONSO, R. B. A. (Orgs.). A Federação em perspectiva: ensaios selecionados. São Paulo: Fundap, 1995. p. 57-75.

AFONSO, J. R. R. Descentralização fiscal: ser ou não ser, não é a questão. Revista de Administração Municipal. Rio de Janeiro, IBAM, v. 42, n. 214, p. 22-33, 1995.

ARRETCHE, M. Estado Federativo e políticas sociais: determinantes da descentralização. Rio de Janeiro: Revan; São Paulo: Fapesp, 2000.

ARRETCHE, M. Federalismo e igualdade territorial: uma contradição em termos? In: ___. Democracia, federalismo e centralização no Brasil. Rio de Janeiro: FGV; Fiocruz, 2012. p. 173-202.

BARCA, F. An agenda for a reformed cohesion policy. A placedbased approach to meeting European Union challenges and expectations. Independent Report prepared at the request of Danuta Hübner, Commissioner for Regional Policy, Brussels, 2009.

BECKER, B.; EGLER, C. Brasil: uma nova potência regional na economia-mundo. Rio de Janeiro: Bertrand Brasil, 2011.

BERTRAND, N.; PEYRACHE-GADEAU, V. Cohésion sociale et coherence territoriale: quel cadre de réflexion pour l'aménagement et le développement? Géographie, économie, société, v. 11, n. 2, p. 85-91, 2009. 
BRASIL. Política Nacional de Desenvolvimento Regional. Brasília: Ministério da Integração Nacional/Secretaria de Políticas de Desenvolvimento Regional, 2005.

BRASIL. I Conferência Nacional de Desenvolvimento Regional. Documento de Referência. Brasília, Ministério da Integração Nacional/Secretaria de Desenvolvimento Regional. 2012. Disponível em: <http://www.integracao. gov.br/c/document_library/get_file?uuid=54bce099503a-4076-8613-d90dd6107c79\&groupId=10157 > . Acesso em: 21/4/2015.

BRENNETOT, A. Pour une géoéthique. Éléments pour une analyse des conceptions de la justice spatiale. L'Espace géographique, n. 1, p. 75-88, 2010.

BRET, B. et al. Justice et injustices spatiales. Paris: Presses Universitaires de Paris Ouest, 2010. 322 p.

$\mathrm{BRET}$, B. Inégalité sociale et cohésion territoriale: pour une lecture rawlsienne du territoire brésilien. Géocarrefour, v. 81, n. 3, p. 183-191, 2006.

BRET, B. Penser l'éthique pour penser le territoire et l'aménagement, à propos du Nordeste du Brésil. L'information géographique, v. 65, n. 3, p. 193-218, 2001.

BUSSI, M. La coopération territoriale: un déficit théorique. In: BUSSI, M. (Org.). Un monde en recomposition: géographie des coopérations territoriales. Rouen: Publications des Universités de Rouen et du Havre, 2009a. p. 11-29.

BUSSI, M. La coopération territoriale: un enjeu renouvelé pour la Géographie? Colloque International de Géographie Politique. Université de Reims, Maison de la Recherche, Département de Géographie, 2-4 avril, p.1-12, 2009b.

BUSSI, M.; DAUDE, E. Le dilemme du prisonnier spatialisé: application aux coopérations territoriales. Actes des Septièmes Rencontres de Théo-Quant, 2005, 12 p. Disponível em: <http://thema.univ-fcomte.fr $\rangle$. Acesso em: $9 / 4 / 2009$.

CRUZ, M. do C. M. T.; DE ARAÚJO, F. B.; BATISTA, S. Consórcios numa perspectiva histórico-institucional. Cadernos Adenauer XII Municípios e Estados: experiências com arranjos cooperativos, n. 4. Rio de Janeiro, Fundação Konrad Adenauer, p. 111-124, 2012.

DALLABRIDA, V. R.; BECKER, D. F. Governança territorial: um primeiro passo na construção de uma proposta teórico-metodológica. Revista Desenvolvimento em Questão, ano 1, n. 2, p. 73-97, 2003.

DAVOUDI, S. Understanding territorial cohesion. Planning, Practice and Research, v. 20, n. 4, p. 433-441, 2005.

DICKINSON, R. E. Ciudad, región y regionalismo. Tradução Angel Abascal Garayoa. Barcelona: Ediciones Omega, 1961.

ESPON. Territory matters for competitiveness and cohesion. Facets of regional diversity and potentials in Europe. ESPON Synthesis Report III, results by autumn 2006, Luxembourg, 2006.

FALUDI, A. Territorial cohesion: an unidentified political objective. Town Planning Review, v. 76, n. 1, p. 1-13, 2005.

FALUDI, A. Territorial Cohesion: Old (French) Wine in New Bottles? Urban Studies, v. 41, n. 7, 1.349-1.365, 2004.
FALUDI, A. Territorial Cohesion Post-2013: To whomsoever it may concern. 24th AESOP Annual Conference, Finland, 2010.16 p.

FALUDI, A.; PEYRONY, J. Cohesion policy contributing to Territorial Cohesion: future scenarios. The European Journal of Spatial Development, n. 43, p. 1-21, 2011.

FARINÓS, J. Gobernanza Territorial para el desarrollo sostenible: Estado de la cuestión y agenda. Boletín de la A.G.E., n. 46, p. 11-32, 2008.

FERRÃO, J. O ordenamento do território como política pública. Lisboa: Fundação Calouste Gulbenkian, 2011.

FIORI, J. L. O Federalismo diante do desafio da globalização. In: SILVA, P. L. B; AFFONSO, R. B. A. (Orgs.) A Federação em perspectiva: ensaios selecionados. São Paulo: Fundap, 1995. p. 57-75.

FONSECA, A. A. M. Instituição e desenvolvimento territorial. O desempenho municipal após a descentralização. Feira de Santana: Universidade Estadual de Feira de Santana, 2005.

FONSECA, A. A. M.; SANTOS, L. L. F.; BOROWSKI, L. M. O localismo e a busca pela justiça espacial no município de Jacobina, Bahia. In: SILVA, A. C. P. (Org.). Geografia política, geopolítica e gestão do território: racionalidades e práticas em múltiplas escalas. Rio de Janeiro: Gramma, 2016. p. 113-138.

GOTTMANN, J. The significance of territory. Charlottesville: University Press of Virginia, 1973.

GOTTMANN, J. La politique des États et leur Géographie. Paris: Librairie Armand Colin, 1952.

GUMUCHIAN, H.; PECQUEUR, B. (Dirs.). La ressource territoriale. Paris: Economica, Anthropos, 2007.

HALL, P.; TAYLOR, R. C. R. La science politique et les trois néo-institutionnalismes. Revue Française de Science Politique, v. 47, n. 3, p. 469-496, 1997.

HARTSHORNE, R. The functional approach in Political Geography. Annals of the Association of American Geographers. Henry Madison Rendal Editor, v. 40, n. 2, p. 94-130, 1950.

LELOUP, F.; MOYART, L.; PECQUEUR, B. La gouvernance territoriale comme un nouveau mode de coordination territoriale? Géographie, Économie, Société, v. 7, n. 4, p. 321-332, 2005.

LÉVY, J. Capital spatial. In: LEVY, J.; LUSSAULT, M. (Dirs.). Dictionnaire de la Géographie et de l'espace des sociétés. Paris: Belin, 2003. p. 514-516.

LÉVY, J. Capital spatial. Le tournant géographique: penser l'espace pour lire le monde. Paris: Belin, 1999.

LIMA, I. A justiça territorial como horizonte ético da governança e a possibilidade amazônica. In: II Congreso Internacional SETED-ANTE: o governo dos territórios, Santiago de Compostela, 2015, p. 175-189.

LOSADA, P. R. A Lei dos Consórcios Públicos: uma estratégia de fortalecimento da Federação brasileira para o desenvolvimento econômico e social, mimeo, 2008. 26 p. LUSSAULT, M. Institution. In: LÉVY, J.; LUSSAULT, M. (Dirs.). Dictionnaire de la Géographie et de l'espace des sociétés. Paris: Belin, 2003. p. 514-516. 
MARCH, J.; OLSEN, J. Rediscovering Institutions: The Organisational Basis of Politics. New York: Free Press, 1989.

MEDEIROS, E. Territorial Cohesion: a conceptual analysis. Institute of Geography and Spatial Planning (IGOT), 2012, 36 p. Disponível em: <http://ww3.fl.ul.pt/ pessoais/Eduardo_Medeiros/docs/PUB_PAP_EM_ Territorial_Cohesion.pdf $>$. Acesso em: 4/4/2015.

MEDEIROS, E. A Coesão Territorial nas NUTS III de Fronteira de Portugal Continental - A iniciativa INTERREG-A e o desenvolvimento regional. O caso da NUT III do Alentejo Central, Tese de Mestrado, CEG, UL, Lisboa, 2005.

NORTH, D. Institution, Institutional Change and Economic Performance. Cambridge: Cambridge University Press, 1990.

OFFNER, J. M. Les territoires de l'action publique locale: fausses pertinences et jeux d'écarts. Revue Française de Science Politique, v. 56, n. 1, p. 27-47, 2006.

OLIVEIRA, F. A crise da Federação: da oligarquia à globalização. In: SILVA, P. L. B.; AFFONSO, R. B. A. (Orgs.). A Federação em perspectiva: ensaios selecionados. São Paulo: Fundap, 1995. p. 77-90.

OTHENGRAFEN, F.; CORNETT, A. A Critical Assessment of the Added Value of Territorial Cohesion. European Journal of Spatial Development, n. 53, 2013, 30 p.

PLANCHE, J. Société civile: un acteur historique de la gouvernance. Paris: Editions Charles Léopold Mayer, 2007.

PRECEDO LEDO, A. La ordenación territorial, ¿una frustración colectiva? Revista Criterios: Revista de Pensamiento Político y Social, n. 7, p. 139-149, dez. 2006.

PRECEDO LEDO, A. Nuevas realidades territoriales para el sigle XXI. Madri: Editorial Sintesis, 2004.

PUTNAM, R. D. Comunidade e democracia: a experiência da Itália Moderna. Rio de Janeiro: Fundação Getúlio Vargas, 1996.

RATZEL, F. Géographie Politique: les concepts fondamentaux. Paris: Fayard, 1987 [1897].

REIS, J. Ensaios de Economia Impura. Coimbra: Almedina, 2009.

RIOS, R. B. Consorciamento intermunicipal no Brasil: experiências de cooperação e desenvolvimento no Território do Vale do Jiquiriçá (BA). Tese de Doutorado em Geografia.
Universidade Federal da Bahia, Salvador, 2015.

RODRIGUES, J. N.; MOSCARELLI, F. Os desafios do pacto federativo e da gestão territorial compartilhada na condução das políticas públicas brasileiras. Geotextos. Salvador, v. 11, n. 1, 2015 (no prelo).

RODRIGUES, J. N. Do comparatismo em Geografia: uma leitura a partir dos modelos de Estado francês e brasileiro. GEOUSP: espaço e tempo, São Paulo, v. 31, p. 119-130, 2012.

RODRIGUES, J. N. La coopération intercommunale, regards croisés entre la France et le Brésil. (Tese de Doutorado) Doutorado em Geografia, Université Jean Moulin Lyon III, Lyon, 2010.

RODRIGUEZ, V. Federalismo e interesses regionais. In: SILVA, P. L. B.; AFFONSO, R. B. A. (Orgs.). A Federação em perspectiva: ensaios selecionados. São Paulo: Fundap, 1995.

RÜCKERT, A. Políticas territoriais, crise europeia e fronteiras. Perspectivas comparadas entre a União Europeia e o Brasil. GEOUSP: espaço e tempo, São Paulo, n. 35, p. 55-69, 2013.

SERVILLO, L. Territorial Cohesion Discourses: Hegemonic Strategic Concepts in European Spatial Planning. Planning Theory \& Practice, v. 11, n. 3, p. 397-416, 2010.

SILVA, A. C. Condicionantes e estratégias da gestão territorial no Consórcio de Desenvolvimento Sustentável - Território Portal do Sertão. Dissertação de Mestrado em Geografia. Universidade Federal da Bahia, Salvador, 2015.

SILVA, C. M. A princesinha do sertão agora é metrópole?! Uma análise do processo de metropolização de Feira de Santana. Dissertação de Mestrado em Geografia. Universidade Federal da Bahia, Salvador, 2014.

SOUZA, C. Políticas públicas: uma revisão de literatura. Sociologias, Porto Alegre, n. 16, p. 20-45, 2006.

STRELEC, T.; FONSECA, F. Alcances e limites da Lei dos Consórcios Públicos: um balanço da experiência consorciativa no estado de São Paulo. Cadernos Adenauer XII Municípios e Estados: experiências com arranjos cooperativos, n. 4. Rio de Janeiro, Fundação Konrad Adenauer, p. 125-140, 2011.

VAN WELL, L. Conceptualizing the logics of territorial cohesion. European Planning Studies, v. 20, n. 9, p. 1.5491.567, 2012.

\footnotetext{
* Uma versão preliminar deste texto foi originalmente publicada na revista Entre-Lugar, Dourados, MS, ano 6, n. 12, $1^{\circ}$ semestre de 2016, p.112-132. A proposta teórico-metodológica vem sendo desenvolvida no âmbito do projeto de pesquisa "Governança territorial na Amazônia brasileira e os seus reflexos sobre as desigualdades em escalas subnacionais", que conta com o apoio da Capes - Edital Pró-Integração, 2014.
} 


\section{Juliana Nunes}

Doutora em Geografia (ênfase em Geografia Política) pela Université Jean Moulin Lyon III. Realizou o mestrado e a graduação em Geografia na Universidade Federal do Rio de Janeiro. Atualmente, é Professora da Graduação e do Programa de Pós-Graduação em Geografia da Universidade Federal Fluminense, e desenvolve pesquisas nos seguintes temas: federalismo brasileiro e território, escalas políticas, políticas públicas, participação política e cooperação territorial.

E-mail: jnunesrodrigues@yahoo.com.br

\section{Antonio Angelo Martins da Fonseca}

Bacharel e licenciado em Geografia pela Universidade Federal da Bahia (1991), mestre em Arquitetura e Urbanismo pela Universidade Federal da Bahia (1995) e doutor em Geografia Humana pela Universidade Federal do Rio de Janeiro (2003). Atualmente é Professor da Graduação e da Pós-Graduação em Geografia/UFBA e desenvolve pesquisas enfocando as relações entre federalismo, governança, dinâmicas locais e regionais e justiça espacial. E-mail: antonio.fonseca@ufba.br 